\title{
Plasmachemical Synthesis and Basic Properties of CoFe2O4 Magnetic Nanoparticles
}

\author{
A. V. Ushakov ${ }^{a, b}$, I. V. Karpov ${ }^{a, b}$, A. A. Lepeshev ${ }^{a, c}$, L. Yu. Fedorov ${ }^{a}$, A. A. Shaikhadinov ${ }^{a}$ \\ ${ }^{a}$ Siberian Federal University, Svobodnyi pr. 79/10, Krasnoyarsk, 660041 Russia \\ ${ }^{b}$ Reshetnev Siberian State Aerospace University, pr. Krasnoyarskii Rabochii, Krasnoyarsk, \\ 660014 Russia \\ ${ }^{c}$ Krasnoyarsk Scientific Center, Siberian Branch, Russian Academy of Sciences, \\ Akademgorodok 50/50, Krasnoyarsk, 660036 Russia \\ e-mail: sfu-unesco@mail.ru
}

\begin{abstract}
Cobalt-ferrite $\left(\mathrm{CoFe}_{2} \mathrm{O}_{4}\right)$ nanoparticles (CFNPs) are obtained using direct plasmachemical synthesis in the plasma of a low-pressure arc discharge. The formation of the CFNPs with an average size of $9 \mathrm{~nm}$ and a narrow granulometric composition is established employing the methods of X-ray structure analysis and transmission microscopy. The CFNP behavior upon high-temperature annealing is analyzed. The CFNP functional groups are determined using the infrared Fourier spectrum. The results of the X-ray energy dispersion confirm the correspondence of the ratio of the number of atoms of each material to the nominal stoichiometry. The basic magnetic properties of the obtained and annealed samples are investigated at room temperature using the vibrating spectrum magnetometry (VSM).
\end{abstract}

\section{Introduction}

In recent years, the obtaining and application of ferrite nanoparticles (FNP) has aroused great interest owing to their unique magnetic and electric properties. Ferrite nanoparticles are used for preparing magnetic fluid seals in the chemical industry, as magnetic lubricants for enriching of nonmagnetic materials, for increasing recording density in magnetic devices, and so on. One of the important applications of FNPs is their use in biology and medicine. Thus, FNPs can serve as "couriers" ensuring the delivery of a medicine or a diagnostic agent [1] to the specified area. The method of incorporating magnetic fluids into tumor tissues, where the subsequent action by a high-frequency magnetic field causes a local heating and destruction of cancer cells (so-called hyperthermia), has been successfully tested [2, 3]. FNPs are widely employed as catalysts for $\mathrm{CO}_{2}$ decomposition [4].

Magnetic properties of FNPs are mainly determined by superparamagnetic relaxation, which manifests itself in nanostructured systems with nanoparticles smaller than $10 \mathrm{~nm}$ in size. At the same time, some distinctive features of FNPs are connected with the presence of a system of aggregates of a certain type, which appear, as a rule, due to magnetodipole interaction between single-domain nanoparticles and the action of magnetic fields. Among spinel ferrites, $\mathrm{CoFe}_{2} \mathrm{O}_{4}$ has the cubic structure. The CFNP physical and chemical properties strongly depend on the method of synthesis. The chemical method of the CFNP synthesis is the most widely employed due to high productivity and simplicity. Two different methods of chemical synthesis of $\mathrm{CoFe}_{2} \mathrm{O}_{4}$ nanocrystals are known today. The first method implies the use of an oxidizing agent such as $\mathrm{H}_{2} \mathrm{O}_{2}$ [5] and $\mathrm{KNO}_{3}$ [6]. The method without an oxidizing agent is more elaborate [7]. Chemical methods are quite complicated and inefficient, and the obtained nanoparticles are contaminated by the products of chemical reactions. The plasmachemical methods of producing magnetic nanoparticles are the most advanced methods [8-12]. The presence of supersaturated vapor of the initial compounds in the plasma and high rates of their annealing lead to the formation of nanoparticles under certain conditions. Variation of the particle energy during condensation makes it possible to obtain various structures of a specific material from amorphous to crystalline; in this case, the sizes and shape of the crystals vary depending on the energy. Mixing of a number of active plasmas makes it possible to carry out plasmachemical reactions of direct synthesis of complex substances; moreover, the reactions proceed without the yield of by-products. This work aims at determining the distinctive features of structural and 
phase state and magnetic properties of the $\mathrm{CoFe}_{2} \mathrm{O}_{4}$ cobalt-ferrite nanoparticles obtained in the plasma of a low-pressure arc discharge.

\section{Experimental}

The experimental setup and the dependence of the powder properties on the conditions of sputtering were considered in detail in $[13,14]$. Stabilization of the arc discharge on the cathode surface was carried out using an electrostatic screen. A compound iron cathode with a cobalt insert was used as the material being sputtered. To ensure plasmachemical reactions, $30 \%$ of $\mathrm{O}_{2}$ $+70 \%$ of Ar gas mixture was puffed into the chamber after its evacuation to a residual pressure of $1 \mathrm{mPa}$. Plasmachemical synthesis was carried out at a gas mixture pressure of $70 \mathrm{~Pa}$. Before evaporation, the cathode was heated up to $500 \mathrm{~K}$. For the indicated pressures, the CFNP powders were produced during $10 \mathrm{~min}$. A stainless steel cooled substrate was used to condensate and collect the resultant powders. The substrate was maintained at a constant temperature of $300 \mathrm{~K}$.

The phase composition of the obtained samples was investigated using the Advance D8 Xray diffractometer in monochromated $\mathrm{CuK} \alpha$ radiation. The scanning was carried out at room temperature in the angular range $30^{\circ}-120^{\circ}$ in $2 \theta$ with a step of $0.04^{\circ}$.

The microstructure of the obtained nanoparticles was analyzed by high-resolution transmission electron microscopy on a JEOL JEM-2100 microscope at an accelerating voltage of $200 \mathrm{keV}$. A sample for electron microscopic study was prepared as follows: the powder was placed in isopropyl alcohol, dispersed in an ultrasonic bath for $2 \mathrm{~min}$, and a solution drop was then placed on a carbon film substrate located on an electron-microscope support grid. The carbon film substrate was $10-15 \mathrm{~nm}$ thick.

The infrared spectra were analyzed in a Nicolet 6700 infrared Fourier spectrometer with a resolution of up to $0.09 \mathrm{~cm}^{-1}$ in the spectral range $25000-20 \mathrm{~cm}^{-1}$. The samples in the form of granules were obtained using $100 \mathrm{mg}$ of dry $\mathrm{KBr}$ and $2 \mathrm{mg}$ of the $\mathrm{CoFe}_{2} \mathrm{O}_{4}$ nanopowder (NP).

The elemental composition was analyzed using the ARL Quant'X X-ray energy dispersive spectrometer.

The magnetic properties of the $\mathrm{CoFe}_{2} \mathrm{O}_{4}$ nanopowder were studied using vibrational magnetometry on a universal high-field measuring system manufactures at the Cryogenic company at room temperature in magnetic fields $0 \pm 20000$ Oe. The field stabilization range was 1 Oe. The values of saturation magnetization Ms were determined by extrapolating function $\mathrm{M}(\mathrm{H}-1)$ for $1 / \mathrm{H} \rightarrow 0$ according to the description in [15].

\section{Results and discussion}

A typical micrograph of the sample is shown in Fig. 1. The powder is an ensemble of strongly agglomerated particles of irregular shape with a size of 8 to $11 \mathrm{~nm}$. As a rule, the particle shape is close to spherical. The investigation of the granulometric composition of the prepared nanoparticles has shown that the obtained nanopowder has a lognormal distribution and an average particle size of $9 \mathrm{~nm}$. The deviation from the average size is no more than $30 \%$.

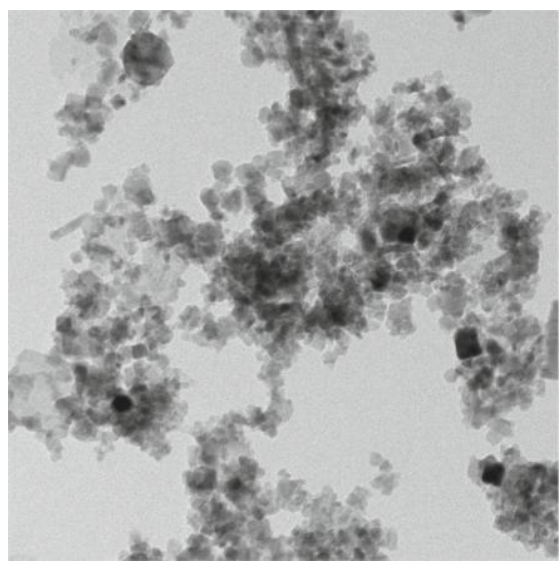

Fig. 1. Typical micrograph of the $\mathrm{CoFe}_{2} \mathrm{O}_{4}$ nanopowder. 
The X-ray diffraction patterns of freshly precipitated and annealed $\mathrm{CoFe}_{2} \mathrm{O}_{4}$ nanoparticles are shown in Fig. 2.

All the figures show only the reflections corresponding to the spinel crystal lattice of the $\mathrm{CoFe}_{2} \mathrm{O}_{4}$ cubic system ( $\mathrm{Fd} 3 \mathrm{~m}$ space group), which correspond well to the standard values from the database of the powder diffraction patterns (JCPDS No. 22-1086) with lattice parameter $a=$ $0.8203 \mathrm{~nm}$. The lattice parameter of the $\mathrm{CoFe}_{2} \mathrm{O}_{4}$ powder is slightly smaller than the standard value, which is most likely due to the features of condensation at underpressure. The deformation in the particles can be due to the action of capillary forces; the static displacements caused by nonuniform deformation in small particles make the greatest contribution to a rootmean-square displacement. Incompleteness of the process of a crystal lattice formation and, correspondingly, a higher concentration of nonequilibrium vacancies are due to the step nature of crystallization, the action of an additional surface pressure, as well as a large contribution of the surface energy to the total free energy of small particles. In this case, structural deformations can be nonuniform over the particle volume. Microstructural characteristics and unit-cell parameters were determined using the Rietveld method $[16,17]$. Simulating the X-ray pattern profile, we used TCH-pseudo-Voigt function [18], which makes it possible to take into account the influence of the instrument component, microstresses, and crystallite sizes on the shape of the peaks. The distinctive features of the peak shapes of the X-ray diffraction pattern indicated the presence of two fractions in the sample, which differ in the crystallite sizes. This conclusion was based on the fact that the diffraction peaks were anomalously sharp. Such a complicated shape could be explained only by the superposition of two peaks substantially differing in width. Therefore, during a full-profile improvement, two fractions with different sizes of crystallites and percentage were introduced to the model. The fullprofile specification of microstructural parameters made it possible to conclude that the bulk of the sample $(\sim 98 \%)$ is a fraction with crystallites $9 \mathrm{~nm}$ in average size, which is in good agreement with the data obtained in microscopic investigations. The macrocrystalline fraction with a crystallite size exceeding $40 \mathrm{~nm}$ in constitutes the remaining $2 \%$ of the material. A strong broadening of the lines makes it possible to state that the amorphous phase occurs together with the crystal phase. To clarify the phase composition of the obtained nanoparticles, we analyzed the specific surface of the freshly precipitated nanoparticles, employing the BET method, from the specific retained volumes determined from the gas chromatograms of heat desorption. According to the formula for determining the mean diameter Dm of nanoparticles in terms of sample density $\rho$ and specific surface $S_{\mathrm{sp}}, \mathrm{D}_{\mathrm{m}}=6 / \rho \mathrm{S}_{\mathrm{sp}}$, we obtained a value of $2 \mathrm{~nm}$. Thus, the prepared $\mathrm{CoFe}_{2} \mathrm{O}_{4}$ nanoparticles have a quite developed surface, which is typical in the conditions of condensation from supersaturated vapor-plasma flows.

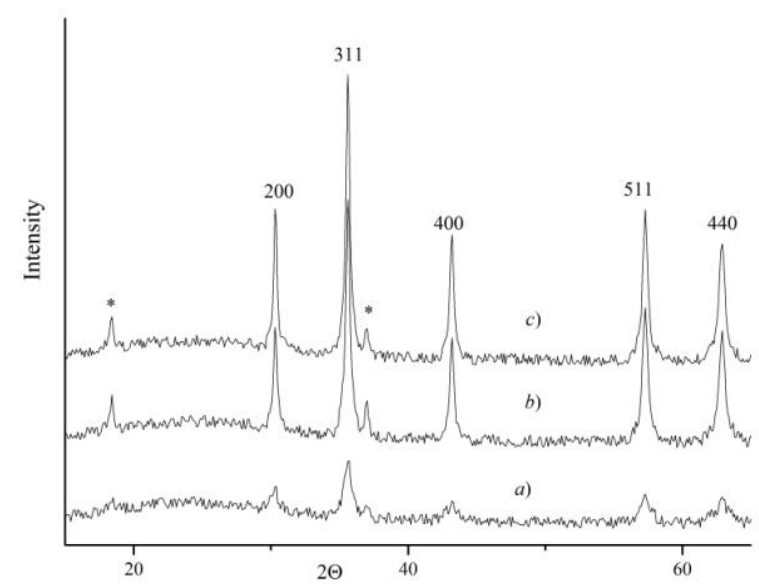

Fig. 2. Diffraction patterns of the resultant $\mathrm{CoFe}_{2} \mathrm{O}_{4}$ nanopowder: (a) freshly precipitated,

(b) annealed to $300^{\circ} \mathrm{C}$, and (c) annealed to $400^{\circ} \mathrm{C}$. 
The $\mathrm{CoFe}_{2} \mathrm{O}_{4}$ infrared Fourier spectra of the freshly prepared and annealed samples are shown in Fig. 3.
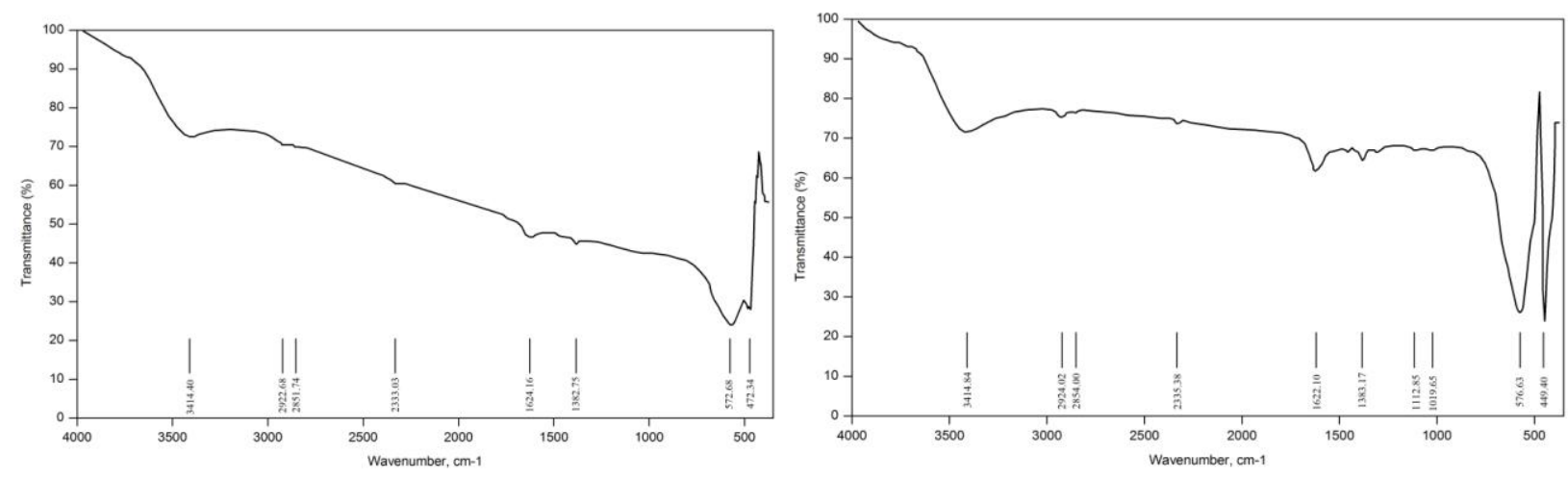

Fig. 3. Infrared spectra of the $\mathrm{CoFe}_{2} \mathrm{O}_{4}$ nanopowder: (a) freshly prepared and (b) annealed to $400^{\circ} \mathrm{C}$

In the far region of the spectrum $\left(\sim 800-400 \mathrm{~cm}^{-1}\right)$, two wide absorption bands can be observed near 572 and $472 \mathrm{~cm}^{-1}$, which are associated with lattice vibrations of $\mathrm{Fe}-\mathrm{O}$ bonds in the $\mathrm{CoFe}_{2} \mathrm{O}_{4}$ tetrahedral and octahedral positions, respectively. Such an assignment of the bands agrees with [19], where two bands at 580 and $480 \mathrm{~cm}^{-1}$ are attributed to $\mathrm{Fe}-\mathrm{O}$ vibrational modes in the magnetite cation sublattices. In the near spectrum region, a wide absorption band can be observed near $3414 \mathrm{~cm}^{-1}$, which corresponds to valence oscillations of the bonded $\mathrm{OH}$ groups. The presence of such groups is an indirect proof of the high activity of the prepared nanoparticles, which is manifested in case of a large specific surface. In this case, a large number of free bonds are formed on the particle surface, and bare atoms (such as $\mathrm{Co}, \mathrm{Fe}$, and $\mathrm{O}$ ) in nanoparticles could adsorb the $\mathrm{OH}^{-}$and $\mathrm{H}^{+}$ions from their surroundings; as a result, the surface enriched with active $\mathrm{OH}$ groups was formed. In addition to the valence oscillations of the bonded $\mathrm{OH}$ groups in the spectrum of the $\mathrm{CoFe} 2 \mathrm{O} 4$ nanoparticles, the absorption band appearing at $1622-1383 \mathrm{~cm}^{-1}$ can be attributed to deformation scissoring vibrations of water residues $\delta(\mathrm{HOH})$.

The results of the X-ray fluorescent energy dispersive spectrometry confirmed that the ratio of the number of atoms in a transition metal in each sample correspond to the nominal stoichiometry. Atomic ratio $\mathrm{Fe}$ : Co of the freshly precipitated as well as the annealed sample (Fig. 4), was about $2: 1$. These results show a stable structure of the $\mathrm{CoFe}_{2} \mathrm{O}_{4}$ crystal spinel at the annealing temperature.

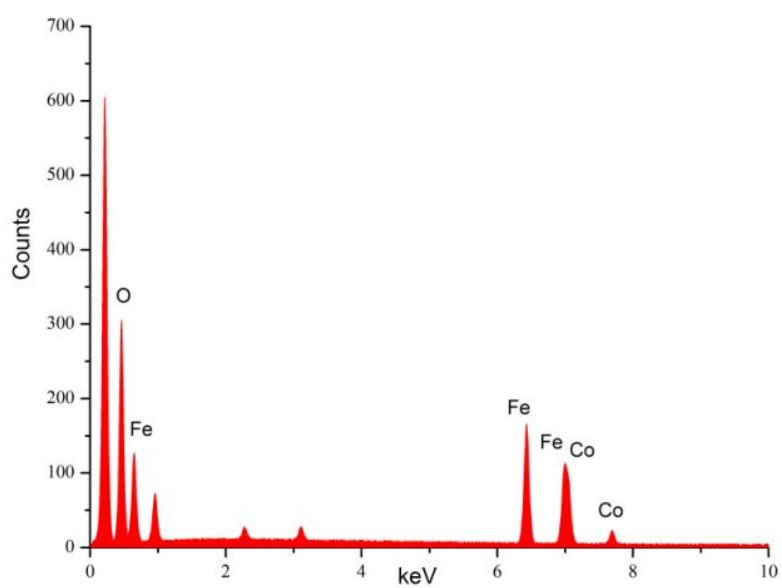

Fig. 4. X-ray fluorescent energy dispersive spectrometry of the $\mathrm{CoFe}_{2} \mathrm{O}_{4}$ nanopowder. 
The results of measurements of magnetization of the initial and annealed $\mathrm{CoFe}_{2} \mathrm{O}_{4}$ nanopowders are shown in Fig. 5. It follows from the figure that saturation magnetization and hysteresis loop are characteristic of all samples in a magnetic field.

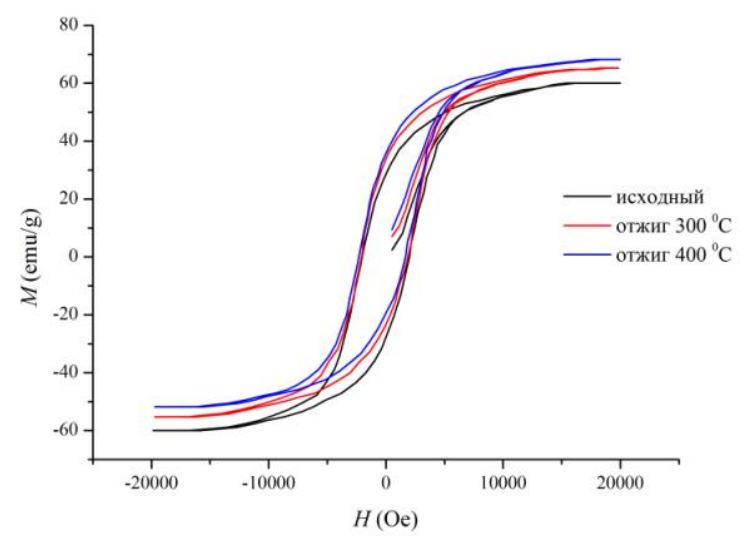

Fig. 5. Magnetization curves $\mathrm{M}$ of the freshly prepared and annealed $\mathrm{CoFe} 2 \mathrm{O} 4$ nanopowder at room temperature.

Saturation magnetization Ms of the samples was 58, 62, and $65 \mathrm{emu} / \mathrm{g}$, respectively. Coercitivity $\mathrm{Hc}$ was 253, 245, and $233 \mathrm{Oe}$, respectively, which is higher than for the $\mathrm{CoFe}_{2} \mathrm{O}_{4}$ nanoparticles obtained in [20]. As expected, saturation magnetization Ms of the samples increases and coercitivity $\mathrm{Hc}$ decreases with an increase in the size of the nanoparticles during annealing. Such a behavior of the nanoparticles is due to the spin glass effect, which appears because of fluctuation-induced nonuniformities of the spins on the nanoparticles surfaces, frozen upon fast cooling [21, 22].

However, the $\mathrm{CoFe}_{2} \mathrm{O}_{4}$ nanoparticles with comparable sizes, but synthesized using another method, have shown a much higher $\mathrm{Ms}$ and significantly lower $\mathrm{H}_{\mathrm{c}}$ [23]. Intracrystalline (technical magnetization) and surface distribution of the spins contribute to the magnetization of the samples being studied. The two contributions compete with each other, especially for a developed surface of nanoparticles. In strong magnetic fields, antiferromagnetism (paramagnetic magnetization) is destroyed due to spin flip. The annealing temperature greatly affects the magnetic properties that are connected to the variation of the valence of cobalt ions and the size and morphology of nanoparticles.

\section{Conclusions}

The $\mathrm{CoFe}_{2} \mathrm{O}_{4}$ nanoparticles have been obtained as a result of sputtering of a compound cathode in the oxygen-containing plasma of a low-pressure arc discharge. It is established that the particles have a spherical shape with an average size of $9 \mathrm{~nm}$ and a developed surface. The $\mathrm{X}$-ray structure analysis has shown that the particles have the spinel crystal lattice of the $\mathrm{CoFe}_{2} \mathrm{O}_{4}$ cubic system ( $\mathrm{Fd} 3 \mathrm{~m}$ space group). The results of the $\mathrm{X}$-ray fluorescent energy dispersive spectrometry have shown that the number of atoms in a transition metal in each sample corresponds to the nominal stoichiometry. The infrared Fourier spectra of the freshly prepared and annealed $\mathrm{CoFe}_{2} \mathrm{O}_{4}$ samples have confirmed a high purity of the obtained nanoparticles. Measurements of the magnetic properties of the initial and annealed (up to $300^{\circ} \mathrm{C}$ and $400^{\circ} \mathrm{C}$ ) $\mathrm{CoFe}_{2} \mathrm{O}_{4}$ nanopowders shows that saturation magnetization $\mathrm{Ms}$ of the samples was 58,62 , and $65 \mathrm{emu} / \mathrm{g}$, respectively and coercitivity Hc was 253, 245, and 233 Oe, respectively.

\section{Acknowledgments}

This study was supported by the Ministry of Education and Science of the Russian Federation within the frames of the State order for 2014-2016 (project no. 11.1287.2014/K). 


\section{References}

1. C. Alexiou, R. Jurgons, R. Schmid, A. Hilpert, C. Bergemann, F. Parak, and H. Iro, J. Magn. Magn. Mater. 293, 389 (2005).

2. I. Skumiel, J. Magn. Magn. Mater. 307, 85 (2006).

3. A. Jordan, R. Scholz, K. Maier-Hauff, M. Johannsen, P. Wust, J. Nadobny, H. Schirra, H. Schmidt, S. Deger, S. Loening, W. Lanksch, and R. Felix, J. Magn. Magn. Mater. 255, 118 (2001).

4. M. H. Khedr and A. A. Farghali, Appl. Catal. B 9, 219 (2005).

5. M. Rajendran, R. C. Pullar, A. K. Bhattacharya, D. Das, S. N. Chintalapudi, and C. K. Majumdar, J. Magn. Magn. Mater. 232, 71 (2001).

6. C. N. Chinnasamy, B. Jeyadevan, K. Shinoda, K. Tohji, D. J. Djayaprawira, M. Takahashi, R. J. Joseyphus, and A. Narayanasamy, Appl. Phys. Lett. 83, 2862 (2003).

7. Y. Qu, H. Yang, N. Yang, Y. Fan, H. Zhu, and G. Zou, Mater. Lett. 6, 3548 (2006).

8. E. Omurzak, J. Jasnakunov, N. Mairykova, A. Abdykerimova, A. Maatkasymova, S. Sulaimankulova, M. Matsuda, M. Nishida, H. Ihara, and T. Mashimo, J Nanosci. Nanotechnol. 7, 3157 (2007).

9. I. Bica, Mater. Sci. Eng., B 68, 59 (1999).

10. D. N. McIlroy, J. Huso, Y. Kranov, J. Marchinek, C. Ebert, S. Moore, E. Marji, and R. Gandy, J. Appl. Phys. 93, 5643 (2005).

11. I. Banerjee, Y. B. Khollam, C. Balasubramanian, R. Pasricha, P. P. Bakare, K. R. Patil, A. K. Das, and S. V. Bhoraskar, Scr. Mater. 54, 1235 (2006).

12. L. Zajickova, P. Synek, O. Jasek, M. Elias, B. David, J. Bursik, N. Pizurova, R. Hanzlikova, and L. Lazar, Appl. Surf. Sci. 255, 5421 (2009).

13. A. V. Ushakov, I. V. Karpov, A. A. Lepeshev, and L. Yu. Fedorov, Remont Vosstanovl. Modernizats., No. 9, 41 (2012).

14. I. V. Karpov, A. V. Ushakov, L. Yu. Fedorov, and A. A. Lepeshev, Tech. Phys. 59, 559 (2014).

15. S. R. Ahmed, S. B. Ogale, G. C. Papaefthymiou, R. Ramesh, and P. Kofinas, Appl. Phys. Lett. 80, 1616 (2002).

16. H. M. Rietveld, J. Appl. Crystallogr. 2, 65 (1969).

17. D. V. Wiles and R. A. Young, J. Appl. Crystallogr. 14, 149 (1981).

18. P. Thompson, D. E. Cox, and J. B. Hastings, J. Appl. Crystallogr. 20, 79 (1987).

19. J. T. Keiser, C. W. Brown, and R. H. Heidersbach, J. Electrochem. Soc. 129, 2686 (1982).

20. V. Sepelak, D. Baabe, D. Mienert, D. Schultze, F. Krumeich, F. J. Litterst, and K. D. Becker, J. Magn. Magn. Mater. 257, 377 (2003).

21. R. H. Kodama, A. E. Berkowitz, E. J. McNiff, and Jr. S. Foner, Phys. Rev. Lett. 77, 394 (1996).

22. S. D. Tiwari and K. P. Rajeev, Phys. Rev. B 72, 104433 (2005).

23. L. J. Zhao, V. Zhang, Y. Xing, S. Y. Song, S. Y. Yu, W. D. Shi, X. M. Guo, J. H. Yang, and F. Lei Cao, J. Solid State Chem. 81, 245 (2008). 